\title{
Influences of the selected additives on the weight loss and organoleptic properties of marinated mussels and squids
}

\author{
Metin Guldas, Canan Hecer \\ Uludag University, Karacabey Vocational School, Department of Food Technology, Karacabey Bursa, \\ Turkey \\ Received December 27, 2010 \\ Accepted May 16, 2012
}

\begin{abstract}
Effects of seven different solutions prepared from various additives (carrageenan, konjac flour, phosphate, yeast extract, xanthan gum and maltodextrin) were used to test for the first time in the marination of experimental seafood. The additives were added into the marination solutions and the samples were analyzed before and after marination. Statistically, the experimental solutions did not cause significant changes in $\mathrm{pH}$, acidity and salt content of the samples $(P<0.05)$. The highest weight gains were obtained from the solution which contained $0.1 \%$ of konjac flour (E425 I) as $4.01,5.21,4.61$ and $4.88 \%$ in the mussels, big squids, diced squids and small squids, respectively. However, this solution was not preferred by the panellists because of its sticky texture. Inversely to red meat products, the solution containing phosphate caused weight loss during marination. The results indicate that the solution containing $0.2 \%$ carrageenan LM (low methoxyl) was the best solution in the marination process. Dipping into this solution caused weight gains of $4.69,2.98,4.04$ and $2.78 \%$ in the big squids, the mussels, the small squids and the diced squids, respectively $(P<0.01)$. The organoleptic properties (mouth feel, flavour and softness) of mussels and squids were also improved by carrageenan LM addition.
\end{abstract}

Sea food, weight loss, marination, carrageenan

Mussel and squid are common sea products obtained from the Mediterranean, Marmara and Aegean coasts of Turkey. As products they can be sold in form of fresh or processed goods. Marinated mussel and squid are highly valued ready-to-eat sea products with a high nutritive value.

Consumption of marinated sea products such as mussel and squid has increased considerably in the last decade in many European countries. In Turkey, the total amount of caught squid was approximately 2100 tonnes (Gokce et al. 2005), and total mussel production was 850 tonnes (Anonymous 2008).

Marinades are solutions that include sugar, spices, oil, organic acids (vinegar, fruit juice and wine), used to improve the tenderness, juiciness, flavour and aroma, and to extend the shelf-life of many types of food (Sheard et al. 2005; Cadun et al. 2008). Either citric acid or kitchen salt $(\mathrm{NaCl})$ are used for improving the taste and flavour in the marination process. Presence of salt affects the texture properties, water holding capacity, isoelectric point and protein function (Barat et al. 2002). In general, however, the use of high salt content in many food products is avoided because of its negative health effects.

There are many studies focused on marination of various fish (Gokoglu et al. 2004; Kilinc and Cakli 2005; Cadun et al. 2008), but studies of marinated mussels and squid are very limited. Generally, an organic acid such as acetic acid or citric acid and table salt are the main ingredients of a marination solution used for fish and other sea foods (Kilinc and Cakli 2005). In marination, the aim is not only to prevent microbiological growth due to low $\mathrm{pH}$, but also to improve the organoleptic properties and soften the texture of the raw material. Organoleptic properties of sea products need to be enhanced to meet the consumers' demand. Weight loss and enhancement of sensory properties in marinated sea

Address for correspondence:

Dr. Metin Guldas

Department of Food Technology,

Karacabey Vocational School, Uludag University

16700 Karacabey Bursa Turkey
Phone: +90 224662065

Fax: +902246765562

E-mail: mguldas@uludag.edu.tr

http://actavet.vfu.cz/ 
foods are the main problems considered by the producers. Various additives have been used in other red and white meat products to prevent or reduce similar problems.

Additives such as carrageenan, konjac flour, phosphate, yeast extract, xanthan gum and maltodextrin are used to enhance the water holding capacity and organoleptic properties in some processed meat products including sausages and salami. Phosphates may affect the water-holding capacity (WHC) of post-rigor muscle by increasing the $\mathrm{pH}$ of the muscle. Salt also helps the extraction of soluble proteins in restructured meat products as water binder (Fennema 1990). Carrageenan serves as natural meat binder and improves the quality of the finished product by enhancing its texture, sliceability, and mouthfeel. Xanthan increases the ability to retain water during and after processing. Maltodextrins have been approved by the U.S. Department of Agriculture for use in meat products as binders. They absorb excess water, and reduce purge during storage. They have a higher water-binding capacity than native potato starch in meat products (Cheng and Sun 2008). Konjac flour was approved by the USDA-FSIS in July 1996 for use in processed meat products to improve water binding capacity (Chin et al. 1998).

In this research, solutions prepared from these additives were used for the first time in the marination of sea foods to decrease weight loss and enhance sensory properties. The aim of this study was to investigate the weight gain and/or weight loss ratios in mussels and squid dipped into different marination solutions, and to determine their organoleptic effects on the marinated products.

\section{Materials and Methods}

Raw material

The sea products used in this study were mussels (Mytilus galloprovincialis, L.) and squids (Loligo vulgaris Lamarck, 1798) supplied fresh from the Turbel Sea Products Processing Factory, located in the Marmara region of Turkey (Mudanya, Bursa). About $200 \mathrm{~kg}$ of samples were used and taken randomly from commercial production. All treatments were done in triplicates. Four groups of products were formed and tested: mussel, big squid, small squid and diced squid. The used mussels were $6-8 \mathrm{~cm}$ long and of average weight 25-30 g, the big squid were 14-17 cm long $(\mathrm{n}=50)$ and the small squid were $9-12 \mathrm{~cm}$ long $(\mathrm{n}=50)$. The squid were eviscerated, washed, boiled in $100{ }^{\circ} \mathrm{C}$ water for $5 \mathrm{~min}$, cooled to $4-7{ }^{\circ} \mathrm{C}$ in a refrigerator and then marinated. The diced squid were obtained from the big squid using a dicing machine in the size of approximately $1 \mathrm{~cm}^{3}$. The mussels were boiled in $100^{\circ} \mathrm{C}$ water for $5 \mathrm{~min}$, their shells and bysus hairs (hair-like thread of mussel) were removed, then they were cooled to $4-7^{\circ} \mathrm{C}$ in a refrigerator, and then marinated.

\section{Marination process}

Seven solutions (six experimental marination solutions and one control solution) were tested. The control solution was the main marination solution and consisted of $3.5 \%$ of citric acid and $2 \%$ of $\mathrm{NaCl}$. The other solutions contained citric acid (3.5\%), $\mathrm{NaCl}(2 \%)$ and one of the following ingredients: carrageenan LM, konjac flour E425 i, phosphate, yeast extract, xanthan gum and maltodextrin. We determined the combination and concentration

Table 1. Composition of the marination solutions.

\begin{tabular}{lccccccc}
\hline Code & E330 & \multicolumn{7}{c}{ E407 } & E425i & E339 & \\
\hline Ingredients/ & Citric Acid & $\mathrm{NaCl}$ & $\begin{array}{c}\text { Carrageenan } \\
\text { LM }\end{array}$ & $\begin{array}{c}\text { Konjac flour } \\
\text { Meat conjac 3 }\end{array}$ & Phosphate & ITY* $^{*}$ & Mixture** $^{* *}$ \\
\cline { 2 - 9 } concentration & $3.5 \%$ & $2 \%$ & $0.2 \%$ & $0.1 \%$ & $0.2 \%$ & $0.1 \%$ & $0.15 \%$ \\
\hline Control & + & + & - & - & - & - & - \\
Solution 1 & + & + & + & - & - & - & - \\
Solution 2 & + & + & - & + & - & - & - \\
Solution 3 & + & + & + & + & - & - & - \\
Solution 4 & + & + & - & - & + & - & - \\
Solution 5 & + & + & + & - & - & - & - \\
Solution 6 & + & + & - & - & - & - & + \\
\hline
\end{tabular}

*ITY - yeast extract, ${ }^{* *}$ mixture consisted of $7.5 \mathrm{~g}$ carrageenan LM (E407), 0.4 xanthan gum (E415, 80 mesh), $1 \mathrm{~g}$ konjac flour (E425i), $0.5 \mathrm{~g} \mathrm{KCl}$ (E 508) and $0.6 \mathrm{~g}$ maltodextrin 
of marination solutions in preliminary tests. Based on the organoleptic tests (taste, flavor, color and texture) we obtained six different marination solutions. Composition of the marination solutions is given in Table 1 .

In the solutions, $\mathrm{KCl}$ was the only ingredient supplied from $\mathrm{K}+\mathrm{S} \mathrm{KALI}$ GmbH (Kassel, Germany). The rest of the ingredients were supplied from Kalys SA-ZA (Saint Ismier, France).

Marination was done by immersing the mussels and squid into the defined solutions for $19 \mathrm{~h}$ at $4{ }^{\circ} \mathrm{C}$. The ratio of product to solution was $1: 1.5$. The products were packaged in $1 \mathrm{~kg}$ PVC bags. Packaged sea foods were stored at $4{ }^{\circ} \mathrm{C}$ and analyzed after $19 \mathrm{~h}$ of marination.

Analytical determinations

The weight loss or weight gain ratios were determined as drained weight basis. The samples were weighed before and after marination to calculate weight difference. The samples were drained at $7-10{ }^{\circ} \mathrm{C}$ for $5 \mathrm{~min}$ before weight measurement. A suspension of $1: 1$ mixture of muscle homogenate and $0.15 \mathrm{M} \mathrm{KCl} \mathrm{p.a.} \mathrm{using}$ a standard $\mathrm{pH}$ meter (PHM210, MeterLab, Copenhagen, Denmark) with a glass electrode (Mettler Toledo InLab 413, Ohio, USA) was used for $\mathrm{pH}$ determination. The acidity of the marinated seafood samples was determined according to Varlik et al. (1993). Salt content was measured using the method proposed by Ludorff and Meyer (1993). All analytical measurements were done as three replicates of each sample were made to obtain the mean value.

Organoleptic evaluation

Organoleptic evaluation was achieved by ten trained panelists according to the method of Ludorff and Meyer (1993) as proposed by Cadun et al. (2008). The variables for the sensory evaluation included appearance, flavour, odour and texture. Maximum score of the test was 30 points meaning first-class quality. Scores from 29.9 to 26 were defined as a second-class quality, 25.9 to 22 as a third-class quality and 21.9 to 12 as a fourth-class quality.

Statistical analysis

The Statistical Package for the Social Sciences version 14.0 (SPSS, Chicago, IL, USA) was used for data analyses. Values are expressed as arithmetic means \pm standard deviations (sd). The differences within groups were analyzed using ANOVA (Analysis of Variance). The means were considered as significant when $P<0.05$ or $P<0.001$ by Tukey honest significance test.

Table 2. Weight gain/loss in the squids and mussels after different marination solutions used.

\begin{tabular}{lcccc}
\hline Treatment & \multicolumn{2}{c}{ Big squid $(\mathrm{g})(\mathrm{n}=5)$} & \multicolumn{2}{c}{ Mussel $(\mathrm{n}=5)$} \\
& mean $(\mathrm{g}) \pm \mathrm{sd}$ & gain/loss $(\%)$ & $982.67 \pm 1.76^{\mathrm{d}}$ & gain/loss $(\%)$ \\
\hline Control & $796.67 \pm 1.76^{\mathrm{e}}$ & - & $1012 \pm 1.70^{\mathrm{b}}$ & +2.98 \\
Solution 1 & $834.07 \pm 1.91^{\mathrm{b}}$ & +4.69 & $1022.1 \pm 1.76^{\mathrm{a}}$ & +4.01 \\
Solution 2 & $838.20 \pm 3.84^{\mathrm{b}}$ & +5.21 & $1001.8 \pm 1.71^{\mathrm{c}}$ & +1.95 \\
Solution 3 & $813.40 \pm 2.30^{\mathrm{c}}$ & +2.09 & $972.9 \pm 1.25^{\mathrm{e}}$ & -1.00 \\
Solution 4 & $780.83 \pm 2.23^{\mathrm{e}}$ & -2.03 & $905.4 \pm 1.19^{\mathrm{f}}$ & +1.22 \\
Solution 5 & $803.6 \pm 1.98^{\mathrm{d}}$ & +1.55 & $1008.3 \pm 1.56^{\mathrm{c}}$ & +0.55 \\
\hline Solution 6 & $849.9 \pm 1.37^{\mathrm{a}}$ & +0.35 & $\mathrm{~g}) \pm \mathrm{sd}$ & \\
\hline
\end{tabular}

Values in a column with different superscripts are significantly different $(P<0.05)$, sd - standard deviation

Table 3. Weight gain/loss ratios in small squids and diced squids after different marination solutions used.

\begin{tabular}{lcccc}
\hline \multirow{2}{*}{ Treatment } & \multicolumn{2}{c}{ Small squid $(\mathrm{g})(\mathrm{n}=5)$} & \multicolumn{2}{c}{ Diced squid $(\mathrm{g})(\mathrm{n}=5)$} \\
& mean $(\mathrm{g}) \pm \mathrm{sd}$ & gain/loss $(\%)$ & mean $(\mathrm{g}) \pm \mathrm{sd}$ & gain/loss $(\%)$ \\
\hline Control & $799 \pm 1.53^{\mathrm{c}}$ & - & $800.33 \pm 1.45^{\mathrm{c}}$ & - \\
Solution 1 & $823.3 \pm 1.60^{\mathrm{a}}$ & +4.04 & $822.60 \pm 1.39^{\mathrm{ab}}$ & +4.78 \\
Solution 2 & $814.6 \pm 0.96^{\mathrm{b}}$ & +4.88 & $826.5 \pm 1.06^{\mathrm{a}}$ & +4.61 \\
Solution 3 & $795.2 \pm 1.14^{\mathrm{c}}$ & +2.27 & $804.3 \pm 0.89^{\mathrm{c}}$ & +2.18 \\
Solution 4 & $822.53 \pm 0.67^{\mathrm{a}}$ & +2.94 & $824.30 \pm 1.85^{\mathrm{a}}$ & +2.99 \\
Solution 5 & $814.53 \pm 1.04^{\mathrm{b}}$ & +1.94 & $815.97 \pm 1.31^{\mathrm{b}}$ & +1.95 \\
Solution 6 & $800.70 \pm 1.15^{\mathrm{e}}$ & +0.21 & $803.07 \pm 1.19^{\mathrm{c}}$ & +0.34 \\
\hline
\end{tabular}

Values in a column with different superscripts are significantly different $(P<0.01)$, sd - standard deviation 
Table 4. Organoleptic evaluation of big squids, mussels, small squids and diced squid after marination in different solutions

\begin{tabular}{lcccc}
\hline Treatment & $\begin{array}{c}\text { Big squid }(\mathrm{n}=10) \\
\text { mean }(\mathrm{g}) \pm \mathrm{sd}\end{array}$ & $\begin{array}{c}\text { Small squid }(\mathrm{n}=10) \\
\text { mean }(\mathrm{g}) \pm \mathrm{sd}\end{array}$ & $\begin{array}{c}\text { Diced squid }(\mathrm{n}=10) \\
\text { mean }(\mathrm{g}) \pm \mathrm{sd}\end{array}$ & $\begin{array}{c}\text { Mussel }(\mathrm{n}=10) \\
\text { mean }(\mathrm{g}) \pm \mathrm{sd}\end{array}$ \\
\hline Control & $28.6 \pm 0.17^{\mathrm{ab}}$ & $28.3 \pm 0.23^{\mathrm{b}}$ & $28.3 \pm 0.23^{\mathrm{b}}$ & $28.4 \pm 0.17^{\mathrm{b}}$ \\
Solution 1 & $29.5 \pm 0.23^{\mathrm{a}}$ & $29.5 \pm 0.15^{\mathrm{ab}}$ & $29.3 \pm 0.12^{\mathrm{a}}$ & $29.3 \pm 0.23^{\mathrm{a}}$ \\
Solution 2 & $19.2 \pm 0.29^{\mathrm{d}}$ & $18.6 \pm 0.45^{\mathrm{c}}$ & $17.6 \pm 0.33^{\mathrm{d}}$ & $16.1 \pm 0.17^{\mathrm{d}}$ \\
Solution 3 & $21.6 \pm 0.20^{\mathrm{c}}$ & $23.3 \pm 0.29$ & $21.2 \pm 0.56^{\mathrm{c}}$ & $20.8 \pm 0.14^{\mathrm{c}}$ \\
Solution 4 & $26.7 \pm 0.17^{\mathrm{ab}}$ & $28.4 \pm 0.17^{\mathrm{a}}$ & $27.7 \pm 0.15^{\mathrm{ab}}$ & $26.6 \pm 0.17^{\mathrm{ab}}$ \\
Solution 5 & $18.3 \pm 0.35^{\mathrm{d}}$ & $17.4 \pm 0.34^{\mathrm{c}}$ & $17.3 \pm 0.12^{\mathrm{d}}$ & $17.8 \pm 0.15^{\mathrm{d}}$ \\
Solution 6 & $21.2 \pm 0.20^{\mathrm{c}}$ & $20.5 \pm 0.29^{\mathrm{d}}$ & $21.2 \pm 0.20^{\mathrm{c}}$ & $22.2 \pm 0.19^{\mathrm{c}}$ \\
\hline
\end{tabular}

Values in the same column with different superscripts are significantly different $(P<0.01)$, sd - standard deviation

Organoleptic evaluation: first-class quality (30 points), second-class quality (29.9-26 points), third-class quality (25.9-22 points), fourth-class quality (21.9-12 points)

\section{Results}

The solutions used did not lead to significant differences $(P<0.05)$ in $\mathrm{pH}$, acidity and salt contents of the samples. The $\mathrm{pH}$ ranged from 3.75 to 4.02 in big squid, 3.70 to 3.99 in mussels, 3.86 to 4.09 in small squid, 3.87 to 3.98 in diced squid. The titratable acidity (\%) ranged from 3.50 to 3.60 in big squid and mussels, from 3.20 to 3.50 in small squid and diced squid. During the $19 \mathrm{~h}$ of marination period, no significant biological activity occurred and $\mathrm{pH}$ and acidity values of all samples did not differ significantly in all the experimental solutions $(P<0.05)$.

The salt content (\%) ranged from 0.74 to 0.87 in the big squid, 2.70 to 2.90 in mussels, 0.64 to 0.74 in small squid and 0.73 to 0.85 in diced squid. The highest weight gains (Table 2) were obtained from the big squid and mussels treated with meat konjac solution (5.21\% and $4.01 \%$, respectively). But in spite of the increase in weight gain ratios, the meat konjac caused a negative effect on the sensory properties in the samples' flesh such as stickiness.

In terms of both sensory properties and weight gains, the best results were obtained from the marination solution containing $0.2 \%$ carrageenan LM (Sol. 1). In addition to the highest scores obtained from the sensory tests (Table 4 ), the solution with $0.2 \%$ carrageenan LM caused a $4.69 \%$ increase in big squid and $2.98 \%$ increase in mussels.

When the small squid samples and diced squid samples were considered (Table 3), the best results in weight gain ratios and sensory scores were also obtained from the solutions containing carrageenan LM (Sol. 1). The Sol. 1 containing carrageenan LM led to the highest weight gain $(4.04 \%)$.

Sol. 1 and 2 caused similar weight gains in mussels and squid (Table 2). However, sticky texture and slippery film on the surface were determined in samples using Sol. 2. The Sol. 3 is a mixture of Sol. 1 and 2 and caused an approximately $2 \%$ weight gain in both mussel and squid samples compared to control. However, in this solution, problems caused by meat konjac were identified. The Sol. 4 containing phosphate led to a weight loss in both samples.

The Sol. 1 (containing $0.2 \%$ carrageenan LM) caused approximately 3\% weight gain in the big squid samples. It was tried in both sizes of squid (big and small). As shown in Tables 2 and 3, the size effect was compared. Bigger squid gained slightly more water than smaller ones because of the larger surface area.

The Sol. 6 lead to an increase of 1.90-1.95\% in weight and unexpected yellowish colour in the marinated samples. The Sol. 7 had no significant effect on weight changes. However, 
during the sensory evaluations of the marinated samples, some negative effects such as sticky structure caused from meat konjac were observed.

\section{Discussion}

The $\mathrm{pH}$ and acidity values of all samples did not differ significantly as values obtained in marinated sardines by Gokoglu et al. (2004). Salt contents were higher in the diced squid than uncut (whole) squid due to diffusion of salt into the samples' flesh as mentioned by Wang et al. (2000). Increased surface area of the squid by cutting or dicing led to higher diffusion of salt into its flesh as mentioned by Fennema (1990). We assume that the slight changes did not cause a significant difference in the weight gain/loss and cannot be a major reason of the weight gains seen in the tested samples (Table 4). When compared to meat products (Fennema 1990), phosphate in Sol. 4 caused the opposite effect (weight loss) in the mussels and squid (Cheng and Sun 2008).

Regarding the organoleptic evaluations, the best results were obtained from the solutions with carrageenan LM, increasing either weight gain ratios or sensory properties. Carrageenan LM, softened the texture of the products, gave way to easier chewing and decreased the irritant effect inside the throat. It did not cause colour changes and precipitation in the marinated product. Meat konjac caused softer texture but also a slippery film on the product surface. The least irritant effect was observed by the panelists. No organoleptic and colour effects were found in the solution using phosphate. Yeast extract (ITY) caused yellowish colour in the products.

\section{References}

Anonymous 2008: Fisheries statistics. State Institute of Statistics, Prime Ministry, Republic of Turkey, Ankara

Barat JM, Rodriguez-Barona S, Andres A, Fito P 2002: Influence of increasing brine concentration in the cod salting process. J Food Sci 65: 1922-1925

Cadun A, Kisla D, Cakli S 2008: Marination of deep-water pink shrimp with rosemary extract and the determination of its shelf-life. Food Chem 109: 81-87

Cheng Q, Sun DW 2008: Factors affecting the water holding capacity of red meat products: A review of recent research advances. Crit Rev Food Sci Nutr 48: 137-159

Chin KB, Keeton JT, Longnecker MT, Lamkey JW 1998: Low fat bologna in a model system with varying types and levels of konjac blends. J Food Sci 63: 808-813

Fennema OR 1990: Comparative water holding properties of various muscle foods. A critical review relating to definitions, methods of measurement, governing factors, comparative data and mechanistic matters. J Muscle Foods 1: 363-381

Gokce G, Metin C, Aydın I, Bayramic I 2005: Squid catching in Izmir Bay using commercial squid nets (Loligo vulgaris Lamarc, 1978). Ege University J Fish Aquat Sci 22: 419-422

Gokoglu N, Cengiz E, Yerlikaya P 2004: Determination of the shelf life of marinated sardine (Sardina pilchardus) stored at $4^{\circ} \mathrm{C}$. Food Control 15: 1-4

Kilinc B, Cakli S 2005c: Chemical, enzymatical and textural changes during marination and storage period of sardine (Sardina pilchardus) marinades. Eur Food Res Technol 221: 821-827

Ludorff W, Meyer V 1973: Fish and fisheries products, basic steps in food control) (Band 6). Verlag Paul Parey, Berlin und Hamburg, Germany, 294 p.

Sheard PR, Nute GR, Richardson RI, Wood JD 2005: Effects of breed and marination on the sensory attributes of pork from Large White and Hampshire-sired pigs. Meat Sci 70: 699-707

Varlik C, Ugur M, Gokoglu N, Gun H 1993: Principle and methods of quality control in sea products. Gida Teknolojisi Dernegi Yayinlari 17, Ankara, 174 p.

Wang D, Tang J, Correia LR 2000: Salt diffusivities and salt diffusion in farmed Atlantic salmon muscle as influenced by rigor mortis. J Food Eng 43: 115-123 